\title{
Audio-vestibular outcomes after transmastoid plugging of superior semicircular canal dehiscence
}

\author{
Fuat Ziylan ${ }^{1}$, Andy J Beynon ${ }^{1,2 *}$, Ronald JE Pennings ${ }^{1}$ and Henricus PM Kunst ${ }^{1}$ \\ ${ }^{1}$ Department of Otorhinolaryngology and Head and Neck Surgery, Radboud University Medical Center, Nijmegen, The Netherlands \\ ${ }^{2}$ Vestibular \& Auditory Evoked Potential Lab, Donders Institute for Brain, Cognition \& Behaviour, Centre for Neuroscience, Radboud University Medical Centre, \\ Nijmegen, The Netherlands
}

\begin{abstract}
Objective: To compare pre- and postoperative outcomes in patients who underwent transmastoid plugging of a superior semicircular canal dehiscence.

Design: Retrospective cohort study

Setting: Subjective as well as objective outcomes in patients with superior semicircular canal dehiscence plugged using the transmastoid approach between 2012 and 2015 in Radboud University Medical Centre.

Main outcome measure: The vestibular signs, auditory signs, dizziness handicap inventory (DHI) questionnaire, cervical vestibular evoked myogenic potential test (cVEMP), pure tone audiogram, speech audiogram and electro-nystagmography were documented.

Results: In total 13 patients were included for analysis, with a mean age of 52.7 years. Nine patients received pre- and postoperative cVEMPs, showing a significant postoperative increase of cVEMP thresholds. In seven patients, pre- and postoperative DHI scores were available showing a significant decrease of their dizziness handicap. No significant pre-postoperative differences were found for all other audio-vestibular tests. No serious complications occurred, and the mean hospital stay was 1.4 day.

Conclusion and recommendation: Transmastoid approach for plugging the dehiscence of the superior canal resulted in significant improvement of cVEMP thresholds and DHI scores. Plugging the dehiscence using the transmastoid approach is recommended, since it is associated with a short hospital stay and low rate of adverse events.
\end{abstract}

\section{Introduction}

Superior semicircular canal dehiscence (SSCD) was first reported by Minor et al. [1] in 1998. A syndrome characterized by the occurrence of vestibular and/or cochlear symptoms, caused by a defect in the bony roof of the superior semicircular canal. Beside the oval and round window, a third window arises because of the opening in the bone. Typical signs and symptoms can be seen at physical examination in patients with SSCD, such as: the Tullio phenomenon, whereby vertigo, dizziness, nausea or nystagmus could be induced by loud sounds, and the Hennebert sign, inducing oscillopsia or nystagmus by maneuvers that change the middle ear and/or intracranial pressure [2]. Other signs and symptoms indicative for SSCD are hyperacusis, tinnitus, aural fullness, autophony, vertigo and nystagmus $[2,3]$.

With respect to audiometric test results, patients with SSCD show an air-bone gap $(A B G)$ for pure low frequency tones on the affected ears, since there is dissipation of acoustic energy because of the third window $[3,4]$. The diagnosis of SSCD can be confirmed by Computerized Tomography (CT-) scan and with vestibular evoked myogenic potential (VEMP) thresholds testing, since it is known that these thresholds are significantly lowered, due to the third window phenomenon $[2,5,6]$.

In the last two decades, several surgical treatments have been developed to repair the dehiscence of the superior semicircular canal [7]. There is still no consensus in the literature which surgical approach is superior to treat patients with SSCD. Minor et al. [1] have described the middle fossa approach (MFA) to plug the dehiscence or to resurface the bone overlying the superior canal. This approach gives a clear exposure of the SSCD. The disadvantage of this approach is the potentially serious surgical complications, because of the retraction of the dura and manipulation of the defect. A more recently described surgical approach is the transmastoid approach (TMA), which is less invasive compared to MFA [8]. Several studies are reported with patient series (i.e. number of included patients $>5$ ), which describe mostly post-operative subjective outcomes after plugging the SSCD using TMA [9-11]. In contrast to subjective outcomes, objective audiovestibular results of this intervention are relatively scarce.

The aim of the present study is to retrospectively compare pre- and post-operative subjective and objective test outcomes in patients with SSCD after the dehiscence is plugged using the TMA.

${ }^{\star}$ Correspondence to: Andy J Beynon, Department of Otolaryngology- Head and Neck Surgery, University Medical Center Nijmegen, Philips van Leydenlaan 15, 6500 HB Nijmegen, The Netherlands, Tel: +31243614965 , Fax: +31243540251 ; E-mail: andy.beynon@radboudumc.nl

Key words: superior semicircular canal dehiscence, plugging, vestibular evoked myogenic potentials, transmastoid approach

Received: July 10, 2020; Accepted: July 24, 2020; Published: July 27, 2020 


\section{Methods}

\section{Subjects}

A retrospective study was performed at the Radboud University Medical Centre, Nijmegen, The Netherlands between 2012 and 2015, including all patients $(n=14)$ that were treated by plugging the SSCD using the TMA. Data regarding patient characteristics, occurrence of complications, hospital stay, dizziness handicap inventory (DHI), preand post-operative clinical findings (including signs and symptoms) and audio-vestibular test results were extracted from hospital records. The DHI is a 25- item questionnaire to quantify the impact of dizziness on everyday life (mild 0-30 points, moderate 31-60 points, and severe 61-100 points) and is divided into three domains: functional, emotional and physical $[12,13]$. All postoperative measurements were obtained at least 2 months after the surgical intervention. The final diagnosis was based on clinical signs and symptoms, audio-vestibular test results and confirmation by a CT-scan. In patients with bilateral SSCD, surgical treatment was performed at the most affected side.

\section{Surgical technique}

A transmastoid approach to the SSCD was performed in all patients to plug the dehiscence. All surgical procedures were performed under general anesthesia by two surgeons. After post-auricular incision, mastoidectomy with atticoantrotomy was performed. Subsequently, the horizontal semicircular canal was identified and the superior semicircular was blue lined. The anterior and the posterior crus of the superior canal were carefully opened and immediately plugged with soft periosteum, which was fixed with fibrin glue. Hereafter, the superior part of the canal was further opened and the superior part of the canal including the dehiscence were blocked with a mixture of bone dust and fibrin glue.

The wound was closed in layers with absorbable sutures and mastoid compression dressing was applied.

\section{Audiometric assessment}

Audiometric tests, i.e. tone and speech audiometry, were performed pre- and post-operatively in a soundproof booth. Air-conduction (AC) thresholds were determined for 250,500, 1000, 2000, 4000 and 8000 $\mathrm{Hz}$ pure tones. To calculate the ABG, bone conduction (BC) thresholds were determined for 500, 1000, 2000, 4000Hz; Pure Tone Average (PTA) as defined as the mean auditory threshold of 500, 1000, 2000 and $4000 \mathrm{~Hz}$. Pre- and post-operative speech reception threshold (SRT) in $\mathrm{dB} \mathrm{nHL}$ and speech recognition score (SRS) in percentage correct phoneme identification were obtained in all patients.

\section{Vestibular assessment}

Pre- and post-operatively vestibular function was evaluated by electronystagmographical (ENG) recordings. Besides assessment of vestibulo-ocular motor movements, rotary chair testing (velocitystep test, VST) and caloric irrigational testing were used to evaluate the presence of possible asymmetrical directional preponderance and/ or vestibular preponderance [14]. For the VST, the patient was seated in a rotary chair. To obtain a horizontal position of the horizontal semicircular canals, the head was horizontally tilted $30^{\circ}$ forwards. To provoke a nystagmus, the chair was accelerated with $2 \% \mathrm{~s}^{2}$ to $0.25 \mathrm{~Hz}$. After a plateau time of 60 seconds, the chair was suddenly stopped with a deceleration of $200 \% \mathrm{~s}^{2}$, inducing a physiological response, i.e. a nystagmus in opposite direction. The maximum slow phase velocity of the nystagmus and time constant were recorded. This was done for both directions to calculate the possible presence of the nystagmus' directional preponderance (asymmetry). For the low frequencies, reactivity and possible vestibular preponderance of individual horizontal semicircular canals were determined by caloric testing using bithermal $\left(30^{\circ}\right.$ and $44^{\circ}$ Celsius, respectively) water irrigation of the external auditory canal [14]. Additionally, a video Head Impulse Test (vHIT) was performed to evaluate the individual function of the semicircular canals in the higher frequency domain, i.e. around $4-6 \mathrm{~Hz}$ [15]. For this, the patient had to focus on a dot on the wall while the examiner made a short but rapid movement (impulse) with the head in the plane of each individual semicircular canal. The eye movements were recorded by a video-camera with a sampling frequency of $100 \mathrm{~Hz}$ (vHIT Ulmer, Synapsys, France). A gain of $>0.7$ for vertical and $>0.8$ for horizontal semicircular canal was defined as normal.

Cervical vestibular evoked myogenic potential (cVEMP) thresholds were obtained for both sternocleidomastoid muscles (SCM), pre- and post-operatively. The patient was instructed to sit in an upright position and was instructed to unilaterally contract the sternocleidomastoid muscle by turning the head to one side. The ipsilateral inhibitory response was evoked by an auditory stimulus of a $500 \mathrm{~Hz}$ tone burst ( $2 \mathrm{~ms}$ rise-fall and plateau time) of a total length of $6 \mathrm{~ms}$. The SCM inhibitory response (i.e. peak-to-peak response of the P13-N23) was recorded using surface electrodes, placed at the SCM (+) referred to the ipsilateral mastoid M1/2 (-) with the ground electrode at Fpz. The cVEMP thresholds were obtained with tone bursts of 500 $\mathrm{Hz}$ in descending steps from $100 \mathrm{~dB}$ nHL to $50 \mathrm{~dB} \mathrm{nHL}$, reducing the stimulus level in $5 \mathrm{~dB}$ steps until no response was identified. The cVEMP threshold was defined as the point at which a peak-peak response of the P13-N23 was just visible (i.e, > 2x standard deviation of the RMS of running noise level). A threshold $\leq 85 \mathrm{~dB} \mathrm{nHL}$ was interpreted as abnormal.

\section{Statistical methods}

Data was analysed with the Statistical Package for Social Sciences (IBM SPSS Statistics for Windows. 21.0 ed. Armonk, NY: IBM Corp.; 2012) was used and a $p$-value below 0.05 was considered as statistically significant. A paired samples T-test was applied to assess the pre- and post-operative difference on cVEMP and audiometric test results.

\section{Results}

\section{Subjects}

Between 2012 and 2015, 14 patients underwent surgical treatment for SSCD syndrome. One patient was treated by plugging through MFA, hence excluded for further analyses, resulting in a study cohort of 13 patients (Table 1). In 7 patients, the surgical procedure was performed on the right side and in 6 patients on the left side. Two patients had bilateral SSCD ( $\# 2$ and \#5), who underwent surgery on the most affected side. The mean hospital stay was 1.4 days with a range of 1 to 2 days. None of the patients had post-operative complications at 12 months follow up.

\section{Subjective assessment}

The pre-operative signs and symptoms of the included patients are presented in table 1 . In general, all patients were satisfied postoperatively. However, one patient (\#7) did not experience an improvement of aural fullness and hyperacusis complaints, but the main complaint of vertigo was totally resolved post-operatively. In 2 patients (\#5 and \#9), tinnitus complaints increased post-operatively. The DHI scores were available for 7 patients, which showed a significant improvement from 42 points pre-operatively to 22 points 
post-operatively $(\mathrm{p}<0.05)$. A significant improvement was obtained in the physical domain $(\mathrm{p}<0.05)$; improvement in the other two domains were not statistically significant. No difference was observed between surgeons.

\section{Objective tests}

\section{Audiometric assessment}

There were no significant differences between the pre- and post-operative audiometric tests, i.e. SDS $(98.3 \%$ pre- versus 97.6\% postoperatively), SRT (31.0 dB nHL pre- versus $27.9 \mathrm{~dB}$ nHL postoperatively), PTA (32.5 dB nHL pre- versus $33.8 \mathrm{~dB} \mathrm{nHL}$ postoperatively) and mean ABG (16.5 dB nHL pre- versus $13.9 \mathrm{~dB} \mathrm{nHL}$ postoperatively) ( $\mathrm{p}>0.05)$. The largest ABG's pre- and post-operatively and the largest gain post-operatively in the ABG's were found for the low frequencies, e.g. for $500 \mathrm{~Hz} 22.3 \mathrm{~dB}$ nHL vs $16.5 \mathrm{~dB}$ nHL (Table 2). In one patient $(\# 6)$, the sensorineural hearing loss was increased from a pre-operative PTA of $37.5 \mathrm{~dB} \mathrm{nHL}$ to a post-operative PTA of $65 \mathrm{~dB} \mathrm{nHL}$.

\section{Vestibular assessment}

Pre- and post-operative vestibular test results are presented in table 3.

Pre-operatively vestibular test results of the semicircular canals were not available in 4 patients (\#1, \#2, \#3 and \#9); post-operative results were not available in 3 patients (\#5, \#10 and \#13). In all patients, pre-operative vHIT gains were normal for all three semicircular canals and the caloric test results showed normal results for both horizontal canals of both ears. One patient showed hyperreflexia and one patient showed hyporeflexia in the VST pre-operatively. Post-operative vHIT showed in two patients lower vestibulo-ocular reflex (VOR) gains (i.e. $<0.7)$ in the anterior canal, and in one patient no response was found in caloric test post-operatively. Cervical VEMPs were found in 10 patients preoperatively, and 10 patients postoperatively. For prevs. postoperative analyses, only patients with pre- ánd postoperative cVEMP thresholds were included, i.e. \#3, \#4, \#7 to \#13 (n=9). In four patients, the pre- and/or post-operative cVEMP results were not available. Pre-operatively, the contralateral ears show an average

Table 1. Patient characteristics

\begin{tabular}{|c|c|c|c|c|c|c|c|c|c|c|c|c|c|}
\hline Patient no. & $\# 1$ & $\# 2$ & $\# 3$ & $\# 4$ & $\# 5$ & $\# 6$ & $\# 7$ & $\# 8$ & $\# 9$ & $\# 10$ & $\# 11$ & $\# 12$ & $\# 13$ \\
\hline Age [yrs] & 46 & 42 & 53 & 57 & 39 & 66 & 50 & 66 & 55 & 44 & 45 & 45 & 57 \\
\hline Gender & $\mathrm{F}$ & M & M & M & $\mathrm{F}$ & M & $\mathrm{F}$ & M & $\mathrm{F}$ & M & $\mathrm{F}$ & $\mathrm{F}$ & $\mathrm{F}$ \\
\hline SSCD Side & $\mathrm{L}$ & $\mathrm{B}$ & $\mathrm{R}$ & $\mathrm{L}$ & $\mathrm{B}$ & $\mathrm{L}$ & $\mathrm{R}$ & $\mathrm{L}$ & $\mathrm{R}$ & $\mathrm{L}$ & $\mathrm{L}$ & $\mathrm{R}$ & $\mathrm{R}$ \\
\hline Operated Side & $\mathrm{L}$ & $\mathrm{R}$ & $\mathrm{R}$ & $\mathrm{L}$ & $\mathrm{R}$ & $\mathrm{L}$ & $\mathrm{R}$ & $\mathrm{L}$ & $\mathrm{R}$ & $\mathrm{L}$ & $\mathrm{L}$ & $\mathrm{R}$ & $\mathrm{R}$ \\
\hline Dizziness & + & + & - & + & + & + & + & + & - & + & + & + & + \\
\hline Hyperacusis & + & + & + & - & - & - & - & + & - & + & - & - & - \\
\hline Autophony & + & + & + & - & + & + & + & + & - & - & + & - & - \\
\hline Tinnitus & + & - & + & + & + & + & + & - & - & + & - & + & - \\
\hline Aural fullness & - & - & + & - & - & - & - & + & + & - & - & - & + \\
\hline Instability & - & - & - & - & + & - & + & - & - & - & - & + & - \\
\hline Vertigo & + & + & - & + & + & + & - & + & - & + & + & + & + \\
\hline Valsalva & + & - & - & - & + & + & - & + & - & + & + & - & - \\
\hline Tullio & - & + & + & - & - & - & + & - & + & + & + & + & - \\
\hline Hennebert sign & + & - & - & + & - & - & - & - & + & + & + & - & + \\
\hline Average ABG [dBHL] & 13 & 5 & 10 & 10 & 36 & 15 & 18 & 13 & 19 & 14 & 10 & 23 & 35 \\
\hline Mean PTA [dBHL] & 20 & 13 & 18 & 40 & 39 & 38 & 25 & 24 & 26 & 70 & 15 & 49 & 48 \\
\hline Hospital stay [days] & 2 & 2 & 1 & 2 & 2 & 1 & 1 & 1 & 2 & 1 & 1 & 1 & 1 \\
\hline
\end{tabular}

Age: age in years; Gender: F: Female; M: Male; SSCD Side: Side of superior semicircular canal dehiscence; L: Left, R: right; B: bilateral; HL: Hearing loss; ABG: Air-bone gap; PTA: pure tone average; NR: Not reported; NA: Not available; DHI: dizziness handicap inventory score; Hospital stay: in days; not reported; + reported

Table 2. Pre- and postoperative audiometrical thresholds and speech perception scores

\begin{tabular}{|c|c|c|c|c|c|c|c|c|c|c|c|c|c|c|c|c|c|c|c|c|c|c|c|c|c|c|c|c|}
\hline \multirow[b]{3}{*}{$\begin{array}{c}\text { Patient } \\
\text { no. }\end{array}$} & \multicolumn{14}{|c|}{ Pre-operative thresholds } & \multicolumn{14}{|c|}{ Post-operative thresholds } \\
\hline & \multicolumn{2}{|c|}{$0.5 \mathrm{kHz}$} & \multicolumn{2}{|c|}{$1 \mathrm{kHz}$} & \multicolumn{2}{|c|}{$2 \mathrm{kHz}$} & \multicolumn{2}{|c|}{$4 \mathrm{kHz}$} & \multicolumn{2}{|c|}{$8 \mathrm{kHz}$} & \multirow{2}{*}{\begin{tabular}{|c|}
$\begin{array}{c}\text { Mean } \\
\text { ABG }_{(0.5-4 k)}\end{array}$ \\
{$[\mathrm{dBnHL}]$} \\
\end{tabular}} & \multirow{2}{*}{\begin{tabular}{|c|} 
PTA \\
[dBnHL]
\end{tabular}} & \multirow{2}{*}{\begin{tabular}{|l|} 
SDS \\
{$[\%]$}
\end{tabular}} & \multirow{2}{*}{\begin{tabular}{|c|} 
SRT \\
{$[\mathrm{dBnHL}]$}
\end{tabular}} & \multicolumn{2}{|c|}{$0.5 \mathrm{kHz}$} & \multicolumn{2}{|c|}{$1 \mathrm{kHz}$} & \multicolumn{2}{|c|}{$2 \mathrm{kHz}$} & \multicolumn{2}{|c|}{$4 \mathrm{kHz}$} & \multicolumn{2}{|c|}{$8 \mathrm{kHz}$} & \multirow{2}{*}{\begin{tabular}{|c|}
$\begin{array}{c}\text { Mean } \\
\text { ABG }_{(0.5-4 k)}\end{array}$ \\
[dBnHL] \\
\end{tabular}} & \multirow{2}{*}{$\begin{array}{c}\text { PTA } \\
{[\mathrm{dBnHL}]}\end{array}$} & \multirow{2}{*}{$\begin{array}{l}\text { SDS } \\
{[\%]}\end{array}$} & \multirow{2}{*}{$\begin{array}{c}\text { SRT } \\
{[\mathrm{dBnHL}}\end{array}$} \\
\hline & BC & AC & BC & $\mathbf{A C}$ & BC & $\mathbf{A C}$ & BC & AC & BC & AC & & & & & BC & AC & BC & $\mathbf{A C}$ & BC & $\mathbf{A C}$ & BC & AC & BC & AC & & & & \\
\hline$\# 1$ & 10 & 20 & 0 & 25 & 10 & 20 & 5 & 15 & 40 & 40 & 13.8 & 20.0 & 100 & 25 & 10 & 25 & 10 & 25 & 10 & 10 & 15 & 15 & 40 & 40 & 7.5 & 18.8 & 100 & 18 \\
\hline$\# 2$ & 0 & 10 & 10 & 10 & 5 & 15 & 15 & 15 & 10 & 10 & 5.0 & 12.5 & - & - & 0 & 10 & 0 & 5 & 5 & 5 & 20 & 20 & 15 & 15 & 3.8 & 10.0 & 100 & 12 \\
\hline$\# 3$ & 0 & 10 & 0 & 20 & 15 & 20 & 15 & 20 & 5 & 5 & 10.0 & 17.5 & 100 & 12 & 5 & 5 & 10 & 15 & 10 & 10 & 15 & 20 & 10 & 10 & 2.5 & 12.5 & - & - \\
\hline$\# 4$ & 30 & 40 & 15 & 30 & 30 & 30 & 55 & 60 & 35 & 35 & 7.5 & 40.0 & 100 & 42 & 35 & 40 & 20 & 25 & 30 & 30 & 50 & 50 & 45 & 60 & 2.5 & 36.3 & 98 & 38 \\
\hline$\# 5$ & 10 & 40 & 0 & 50 & 0 & 30 & 0 & 35 & 10 & 30 & 36.3 & 38.8 & 100 & 46 & 15 & 45 & 10 & 50 & 10 & 40 & 15 & 40 & 0 & 35 & 31.3 & 43.8 & - & - \\
\hline$\# 6$ & 15 & 40 & 10 & 35 & 30 & 30 & 40 & 45 & 25 & 45 & 13.8 & 37.5 & 96 & 31 & 10 & 35 & 30 & 65 & 40 & 75 & 45 & 85 & 90 & 90 & 33.8 & 65.0 & 85 & 58 \\
\hline$\# 7$ & 5 & 30 & 15 & 35 & 5 & 10 & 15 & 25 & 25 & 25 & 15.0 & 25.0 & 100 & 23 & 10 & 35 & 5 & 15 & 15 & 15 & 20 & 25 & 50 & 70 & 10.0 & 22.5 & 100 & 22 \\
\hline$\# 8$ & 0 & 20 & 0 & 5 & 15 & 15 & 30 & 55 & 45 & 45 & 12.5 & 23.8 & 100 & 20 & 10 & 15 & 5 & 10 & 15 & 15 & 55 & 65 & - & 65 & 5.0 & 26.3 & 100 & 15 \\
\hline$\# 9$ & 5 & 35 & 5 & 35 & 10 & 10 & 10 & 25 & - & 60 & 18.8 & 26.3 & 100 & 22 & 30 & 40 & 20 & 35 & 10 & 15 & 5 & 25 & 50 & 90 & 12.5 & 28.8 & - & - \\
\hline$\# 10$ & 65 & 85 & 60 & 70 & 45 & 65 & 55 & 60 & - & 100 & 13.8 & 70.0 & - & - & 55 & 85 & 55 & 85 & 60 & 70 & 50 & 80 & - & - & 25.0 & 80.0 & - & - \\
\hline$\# 11$ & 5 & 25 & 10 & 20 & 5 & 5 & 0 & 10 & 25 & 25 & 10.0 & 15.0 & 100 & 20 & 5 & 20 & 15 & 25 & 5 & 5 & 5 & 10 & 20 & 25 & 7.5 & 15.0 & 100 & 15 \\
\hline$\# 12$ & 15 & 60 & 15 & 45 & 30 & 35 & 35 & 55 & - & 70 & 25.0 & 48.8 & 95 & 37 & 5 & 20 & 15 & 30 & 25 & 25 & 40 & 40 & - & 65 & 7.5 & 28.8 & 95 & 33 \\
\hline$\# 13$ & 15 & 40 & 15 & 45 & 15 & 40 & 10 & 65 & 40 & 95 & 33.8 & 47.5 & 90 & 63 & 15 & 45 & 15 & 45 & 35 & 50 & 15 & 70 & - & - & 32.5 & 52.5 & 100 & 40 \\
\hline Mean & \multicolumn{2}{|c|}{22.3} & \multicolumn{2}{|c|}{20.4} & \multicolumn{2}{|c|}{8.8} & \multicolumn{2}{|c|}{15.4} & & & 16.5 & 32.5 & \begin{tabular}{|l|}
98.3 \\
\end{tabular} & 31.0 & \multicolumn{2}{|c|}{16.5} & 16 & 6.5 & 7. & 3 & 15 & & & & 13.9 & 33.8 & 97.6 & 27.9 \\
\hline
\end{tabular}

ABG: Air-bone gap; Average ABG: Average ABG of 500, 1000, 2000 and 4000 Hz; PTA: Pure tone average of 500, 1000, 2000 and 4000 Hz; SDS: speech discrimination score in \%; SRT: speech reception threshold in $\mathrm{dB} \mathrm{nHL}$ 
Table 3. Pre- and postoperative vestibular results.

\begin{tabular}{|c|c|c|c|c|c|c|c|c|}
\hline & \multicolumn{3}{|c|}{ Pre-operative } & \multicolumn{4}{|c|}{ Post-operative } & \multirow[b]{2}{*}{ cVEMP [dBnHL] } \\
\hline & $V S T$ & Calorics & $v H I T$ & $c V E M P[d B n H L]$ & $V S T$ & Calorics & $v H I T$ & \\
\hline Patient no. & & & & ipsi (contra) & & & & ipsi (contra) \\
\hline \#1 & NA & NA & NA & NA (NA) & Normal & Normal & NA & NA (NA) \\
\hline$\# 2$ & NA & NA & NA & NA (NA) & Normal & No Response & NA & NA (NA) \\
\hline$\# \mathbf{3}$ & NA & NA & NA & $65(75)$ & Normal & Normal & Normal & $100(100)$ \\
\hline$\# 4$ & Normal & Normal & NA & $65(100)$ & Normal & Normal & Normal & $100(95)$ \\
\hline$\# 5$ & Normal & Normal & NA & $45(70)$ & NA & NA & NA & NA (NA) \\
\hline$\# 6$ & Normal & Normal & Normal & NA (NA) & Normal & Normal & Normal & $100(100)$ \\
\hline$\# 7$ & Normal & Normal & Normal & $75(85)$ & Normal & Normal & Normal & $100(80)$ \\
\hline$\# 8$ & Normal & Normal & Normal & $60(100)$ & Normal & Normal & Low gain & $100(100)$ \\
\hline$\# 9$ & NA & NA & NA & 80 (100) & Normal & Normal & Normal & $100(100)$ \\
\hline$\# 10$ & Light hyporeflexia & Normal & Normal & $95(100)$ & NA & NA & NA & $100(100)$ \\
\hline$\# 11$ & Normal & Normal & Normal & $70(97)$ & Normal & Normal & Normal & $95(90)$ \\
\hline$\# 12$ & Normal & Normal & NA & $70(90)$ & Normal & Normal & Low Gain & $90(85)$ \\
\hline$\# 13$ & Normal & Light hyperreflexia & Normal & $100(92)$ & NA & NA & NA & $100(100)$ \\
\hline mean & & & & $73(92)$ & & & & $99(95)$ \\
\hline
\end{tabular}

VST: velocity-step test; Calorics: caloric testing; vHIT: video Head Impulse Test; cVEMP: cervical Vestibular Evoked Myogenic Potential; NA: Not available. cVEMP thresholds are shown in $\mathrm{dB}$ nHL for the affected ipsilateral (in bold) and contralateral side (between brackets).

\section{cVEMP Thresholds}

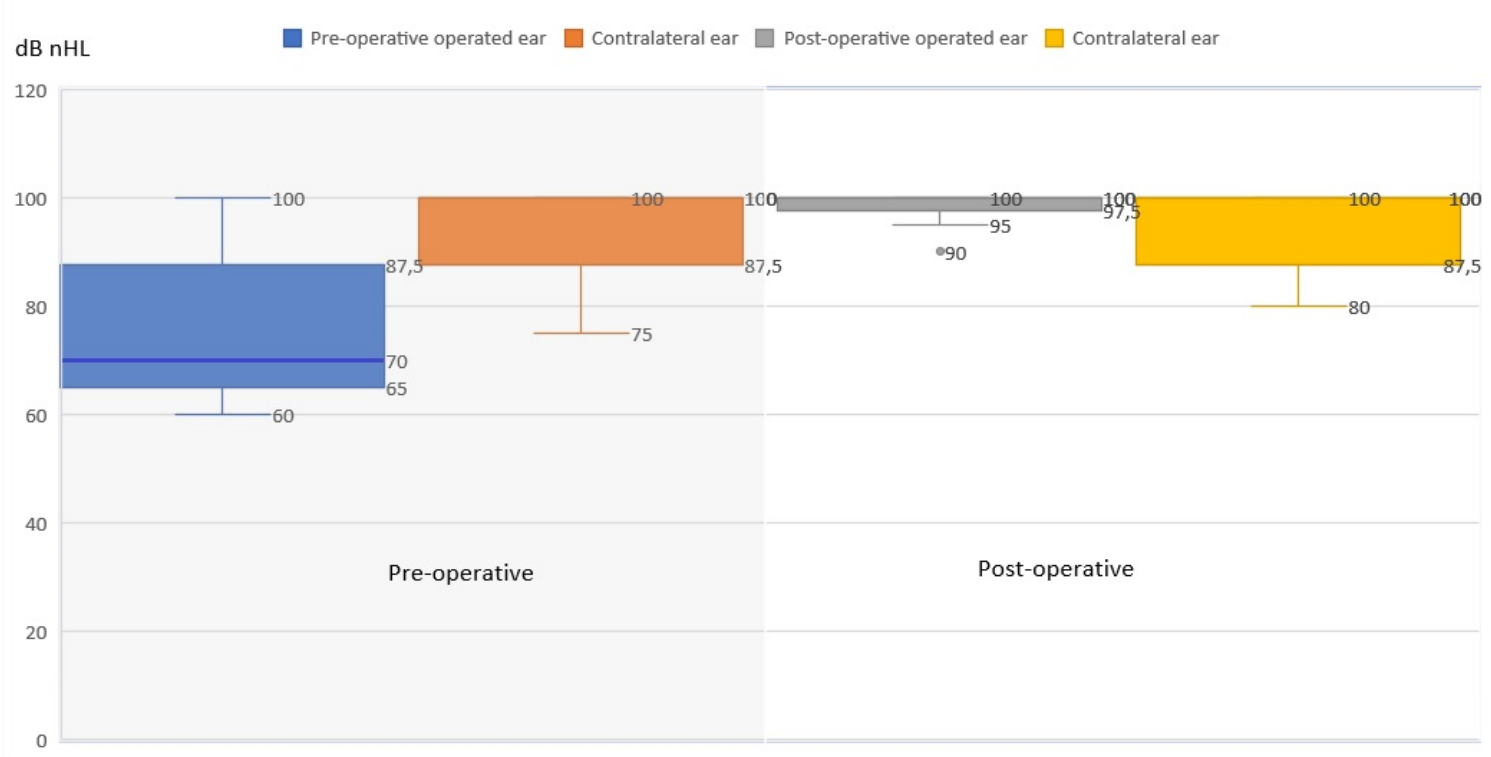

Figure 1. Box Plot of pre- and post-operative cVEMP thresholds. Median, minimum, maximum, upper and lower quartiles representing pre- and post-operative cervical vestibulair evoked myogenic potential (cVEMP) thresholds for the affected ears $(\mathrm{n}=9$ ): a significant postoperative increase of cVEMP threshold was found after plugging ( $<<0.01$ ).

cVEMP threshold of $92 \mathrm{~dB}$ nHL versus $73 \mathrm{~dB}$ nHL for the affected ipsilateral ears. The mean post-operative cVEMP thresholds for the affected ear significantly improved and normalized in all patients, i.e. from 73 to $99 \mathrm{~dB} \mathrm{nHL}(\mathrm{p}<0.01)$ (Figure 1). The contralateral ears did not show any postoperative difference with preoperative thresholds, i.e. 92 vs. $95 \mathrm{~dB} \mathrm{nHL}$ pre- vs. postoperatively respectively ( $\mathrm{p}>0.05)$. The median score for pre-operative cVEMP test for the operated ears was $70 \mathrm{~dB} \mathrm{nHL}$ and post-operatively $100 \mathrm{~dB} \mathrm{nHL}$, for the unoperated ears the median score was pre- and post-operatively the same: $100 \mathrm{~dB} \mathrm{nHL}$.

\section{Discussion}

In this retrospective cohort study, we compared the pre- and postoperative subjective complaints and objective tests after plugging of the
SSCD through TMA. The typical signs and symptoms for SSCD were also identified in our patient population pre-operatively $[2,3]$.

Since the DHI is a questionnaire to quantify the impact of dizziness on everyday life, we used the test to measure the complaints of the included patients $[12,13]$. In all patients the DHI scores improved post-operatively. Crane et al. [16] reported a significant improvement of $59 \%$ of the mean score post-operatively in patients in which the dehiscence is plugged through MFA $(\mathrm{p}<0.05)$. Bogle et al. [11] reported in patients with a DHI score $>30$, a significant improvement of the DHI score after plugging through TMA. In our cohort, a significant improvement of the DHI score was achieved in all patients, including patients with a DHI score $<30$. Bogle et al. [11] did not report data of 
the DHI subdomains. However, Crane et al. [16] reported a significant improvement in all domains in the patients plugged through MFA. Similar to Crane et al. [16] this study observed an improvement in all domains, although only statistically significant in the physical domain. Besides the improvement of the total DHI scores, the present study showed that, in general, all other complaints diminished in all patients.

Hospital stay after surgical treatment is a commonly used criterion in comparing different techniques. In our cohort, the mean hospital stay post-operatively was 1.4 days with a maximum stay of 2 days. Mean hospital stay after plugging the SSCD through MFA varied from 2.5 to 7.8 days, and one study even reported a mean stay at the intensive care unit of 2.7 days $[7,17,18]$.

Testing the VEMP has proven to be a highly sensitive tool to diagnose SSCD [19-22]. Even though VEMP test shows no significant correlation with vestibular and most auditory symptoms or their severity [23]. All patients in our cohort showed a normalization of the cVEMP thresholds post-operatively. Different types of outcome measures for cVEMP tests are described in the literature: normal hearing level (nHL), sound pressure level (SPL) and peak sound pressure level (pSPL) $[17,18,21,24-26]$. In the present study we have used $\mathrm{dB} \mathrm{nHL}$ and thresholds below $90 \mathrm{~dB}$ are suggestive for SSCD. The cut-off thresholds suggestive for SSCD varies between $\leq 75$ (SPL) and $\leq 90 \mathrm{~dB}$ (nHL) in the literature, but currently there is no consensus for abnormal cut-off thresholds $[17,1824,25,27]$. Similar to this study, Thomeer et al. [18] used SPL and $90 \mathrm{~dB}$ cut-off point for abnormal thresholds and reported an improvement of thresholds in all patients. In $54 \%$ of the patients, normalization of thresholds was obtained by plugging the SSCD through the MFA approach [18]. Two studies accomplished $100 \%$ normalization of the thresholds by plugging and resurfacing the SSCD through MFA or TMA, although these studies include a total of 10 patients combined [18,27]. Resurfacing of the SSCD is the repair of the continuity of the bone overlying the canal using bone, fascia or cartilage. The recurrence rate of SSCD is higher when only resurfacing is performed compared to plugging of SSCD, therefore according to the literature, this technique is less often applied to treat SSCD [28].

A limitation of our study is the absence of additional ocular VEMP data, since it was reported that oVEMPs might have slightly better sensitivity and specificity to diagnose SSCD: cVEMP between $80 \%$ $100 \%$, while sensitivity and specificity for oVEMPs are more than $90 \%$ [22]. Recently, clinical applications and methodological pitfalls of both c- and o-VEMPs are reported by Rosengren et al. [29] showing that also oVEMPs do play a substantial role in the diagnosis of SSCD [19].

Another shortcoming of the study is that cVEMP and DHI data was not available for all 13 patients, so although statistical differences were found, our analyses are based on a limited population.

Pre-operative vestibular tests other than cVEMP, including VST, calorics and vHIT, were normal in most of the patients $(>70 \%)$. In the pre-operative VST, calorics and VHIT, there was no difference between the affected and contralateral sides. Results of vestibular tests, other than cVEMP, seem to lack sensitivity to diagnose SSCD. No significant difference was observed in this study between the pre- and postoperative vestibular test results of the semicircular canals. However, one subject showed no caloric responses postoperatively, but normal vestibular reactivity to rotary chair testing. Besides the fact that it is known that caloric irrigation is sensitive to many external confounders (e.g. inefficient irrigation, thick bone), based on the available data we do not have an explanation for the absence of this response. The fact that two subjects showed lower gains in the vHIT, might be explained by the surgical intervention of this semicircular canal: it is very plausible that plugging the anterior semicircular canal obviously led to a hypofunction, reflected as a decrease of the vestibulo-ocular reflex gain of this specific canal.

The present study observed the largest ABG's in the low frequencies, as described in other SSCD patients [3]. The largest post-operative gain in the ABG's was in the low frequencies and the mean change of the ABG and the PTA was minimal. Post-operative change of the ABG, PTA, SDS and SRT results were similar to other studies in which plugging was performed through MFA or TMA [10,17,18,21,24,30-32]. Two of the more serious adverse events of surgical treatment of SSCD are sensorineural hearing loss (SNHL) (5-40\%) and facial paralysis (4.2$6.1 \%)[7,18,21,24,27,31,33,34]$. In this study, one patient had a postoperative PTA change of $>10 \mathrm{~dB}$, without prior surgery to the affected ear. It is not clear what the underlying reason could be since no surgical complications were reported. In patients treated with plugging the dehiscence through MFA, SNHL is more often described, compared to plugging through TMA $[7,10,35]$. Other serious complications, such as facial paralysis and CSF leakage were not observed in our cohort but is more often described in patients plugged through MFA [31,34]. Furthermore, a higher recurrence rate of disease was described in the patients treated through MFA compared to TMA [36]. In this study cohort, no revision surgery was needed. Since the different types of surgical treatment of SSCD do not show significant hearing improvement and/or the risk for postoperative hearing loss, surgical intervention is recommended in highly disabled patients by vestibular symptoms.

\section{Conclusion}

This study, although based on a small number of patients, shows no difference between pre- and post-operative audio-vestibular semicircular canal tests, but a significant improvement of cVEMP test results when the dehiscence is plugged in SSCD patients through TMA. Postoperatively, cVEMP thresholds were found at normal (i.e. higher) stimulation levels, confirming the reported decrease of subjective complaints. Patients plugged through TMA have a relatively short hospital stay and a low adverse event, such as facial paralysis and SNHL. Therefore, for the occlusion of the dehiscence in patients with SSCD, we recommend the transmastoid approach (TMA).

\section{References}

1. Minor LB, Solomon D, Zinreich JS, Zee DS (1998) Sound- and/or pressure-induced vertigo due to bone dehiscence of the superior semicircular canal. Arch Otolaryngol Head Neck Surg 124: 249-258. [Crossref]

2. Minor LB (2005) Clinical manifestations of superior semicircular canal dehiscence. Laryngoscope 115: 1717-1727. [Crossref]

3. Zhou G, Gopen Q, Poe DS (2007) Clinical and Diagnostic Characterization of Cana Dehiscence Syndrome: A Great Otologic Mimicker. Otol Neurotol 28: 920-926. [Crossref]

4. Minor LB, Carey JP, Cremer PD, Lustig LR, Streubel SO, et al. (2003) Dehiscence of bone overlying the superior canal as a cause of apparent conductive hearing loss. Otol Neurotol 24: 270-278. [Crossref]

5. Brantberg K, Bergenius J, Tribukait A (1999) Vestibular-evoked myogenic potentials in patients with dehiscence of the superior semicircular canal. Acta Otolaryngol 119: 633-640. [Crossref]

6. Belden CJ, Weg N, Minor LB, Zinreich SJ (2003) CT evaluation of bone dehiscence of the superior semicircular canal as a cause of sound- and/or pressure-induced vertigo. Radiology 226: 337-343. [Crossref]

7. Ziylan F, Kinaci A, Beynon AJ, Kunst HP (2017) A Comparison of Surgical Treatments for Superior Semicircular Canal Dehiscence: A Systematic Review. Otol Neurotol 38: 1-10. [Crossref] 
8. Crovetto M, Areitio E, Elexpuru J, Aguayo F (2008) Transmastoid approach for resurfacing of Superior Semicircular Canal dehiscence. Auris Nasus Larynx 35: 247-249.

9. Beyea JA, Agrawal SK, Parnes LS (2012) Transmastoid semicircular canal occlusion: a safe and highly effective treatment for benign paroxysmal positional vertigo and superior canal dehiscence. Laryngoscope 122: 1862-1866. [Crossref]

10. Zhao YC, Somers T, van Dinther J, Vanspauwen R, Husseman J, et al. (2012) Transmastoid repair of superior semicircular canal dehiscence. J Neurol Surg B Skull Base 73: 225-229. [Crossref]

11. Bogle JM, Lundy LB, Zapala DA, Copenhaver A (2013) Dizziness handicap after cartilage cap occlusion for superior semicircular canal dehiscence. Otol Neurotol 34: 135-140. [Crossref]

12. Jacobson GP, Newman CW (1990) The development of the Dizziness Handicap Inventory. Arch Otolaryngol Head Neck Surg 116: 424-427. [Crossref]

13. Whitney SL, Wrisley DM, Brown KE, Furman JM (2004) Is perception of handicap related to functional performance in persons with vestibular dysfunction? Otol Neurotol 25: 139-143. [Crossref]

14. Oonk AM, Beynon AJ, Peters TA, Kunst HP, Admiraal RJ, et al. (2015) Vestibular function and temporal bone imaging in DFNB1. Hear Res 327: 227-234.

15. Macdougall HG, McGarvie LA, Halmagyi GM, Curthoys IS, Weber KP (2013) The video Head Impulse Test (vHIT) detects vertical semicircular canal dysfunction. PLoS One 8: e61488. [Crossref]

16. Crane BT, Minor LB, Carey JP (2008) Superior canal dehiscence plugging reduces dizziness handicap. Laryngoscope 118: 1809-1813. [Crossref]

17. Saliba I, Maniakas A, Benamira LZ, Nehme J, Benoit M, et al. (2014) Superior canal dehiscence syndrome: clinical manifestations and radiologic correlations. Eur Arch Otorhinolaryngol 271: 2905-2914. [Crossref]

18. Thomeer H, Bonnard D, Castetbon V, Franco-Vidal V, Darrouzet P, et al. (2015) Long-term results of middle fossa plugging of superior semicircular canal dehiscences: clinically and instrumentally demonstrated efficiency in a retrospective series of 16 ears. Eur Arch Otorhinolaryngol 273: 1689-1696. [Crossref]

19. Welgampola MS, Myrie OA, Minor LB, Carey JP (2008) Vestibular-evoked myogenic potential thresholds normalize on plugging superior canal dehiscence. Neurology 70 : 464-472. [Crossref]

20. Kantner C, Gurkov R (2012) Characteristics and clinical applications of ocular vestibular evoked myogenic potentials. Hear Res 294: 55-63. [Crossref]

21. Niesten ME, McKenna MJ, Herrmann BS, Grolman W, Lee DJ (2013) Utility of cVEMPs in bilateral superior canal dehiscence syndrome. Laryngoscope 123: 226-232. [Crossref]

22. Zuniga MG, Janky KL, Nguyen KD, Welgampola MS, Carey JP (2013) Ocular versus cervical VEMPs in the diagnosis of superior semicircular canal dehiscence syndrome. Otol Neurotol 34: 121-126. [Crossref]
23. Noij KS, Wong K, Duarte MJ, Masud S, Dewyer NA, et al. (2018) Audiometric and cVEMP Thresholds Show Little Correlation With Symptoms in Superior Semicircular Canal Dehiscence Syndrome. Otol Neurotol 39: 1153-1162. [Crossref]

24. Crane BT, Lin FR, Minor LB, Carey JP (2010) Improvement in autophony symptoms after superior canal dehiscence repair. Otol Neurotol 31: 140-146. [Crossref]

25. Fiorino F, Barbieri F, Pizzini FB, Beltramello A (2010) A dehiscent superior semicircular canal may be plugged and resurfaced via the transmastoid route. Otol Neurotol 31: 136-139. [Crossref]

26. Brandolini C, Modugno GC (2012) Do signs of natural plugging of superior semicircular canal dehiscence exist? Am J Otolaryngol 33: 268-271. [Crossref]

27. Phillips D, Souter MA, Vitkovic J, Briggs RJ (2010) Diagnosis and outcomes of middle cranial fossa repair for patients with superior semicircular canal dehiscence syndrome. J Clin Neurosci 17: 339-341. [Crossref]

28. Vlastarakos PV, Proikas K, Tavoulari E, Kikidis D, Maragoudakis P, et al. (2009) Efficacy assessment and complications of surgical management for superior semicircular canal dehiscence: a meta-analysis of published interventional studies. Eur Arch Otorhinolaryngol 266: 177-186. [Crossref]

29. Rosengren SM, Colebatch JG, Young AS, Govender S, Welgampola MS (2019) Vestibular evoked myogenic potentials in practice: Methods, pitfalls and clinical applications. Clin Neurophysiol Pract 4: 47-68. [Crossref]

30. Ward BK, Agrawal Y, Nguyen E, Della Santina CC, Limb CJ, et al. (2012) Hearing outcomes after surgical plugging of the superior semicircular canal by a middle cranial fossa approach. Otol Neurotol 33: 1386-1391. [Crossref]

31. Goddard JC, Wilkinson EP (2014) Outcomes following Semicircular Canal Plugging Otolaryngol Head Neck Surg 151: 478-483. [Crossref]

32. Wenzel A, Ward BK, Ritzl EK, Gutierrez-Hernandez S, Della Santina CC, et al. (2015) Intraoperative neuromonitoring for superior semicircular canal dehiscence and hearing outcomes. Otol Neurotol 36: 139-145. [Crossref]

33. Mikulec AA, Poe DS, McKenna MJ (2005) Operative management of superior semicircular canal dehiscence. Laryngoscope 115: 501-507. [Crossref]

34. Niesten ME, McKenna MJ, Grolman W, Lee DJ (2012) Clinical factors associated with prolonged recovery after superior canal dehiscence surgery. Otol Neurotol 33: 824-831. [Crossref]

35. Van Haesendonck G, Van de Heyning P, Van Rompaey V (2016) Retrospective cohort study on hearing outcome after transmastoid plugging in superior semicircular canal dehiscence syndrome: Our Experience. Clin Otolaryngol 41: 601-606. [Crossref]

36. Schwartz SR, Almosnino G, Noonan KY, Banakis Hartl RM, Zeitler DM, et al (2019) Comparison of Transmastoid and Middle Fossa Approaches for Superior Canal Dehiscence Repair: A Multi-institutional Study. Otolaryngol Head Neck Surg 161 130-136. [Crossref]

Copyright: (C2020 Ziylan F. This is an open-access article distributed under the terms of the Creative Commons Attribution License, which permits unrestricted use, distribution, and reproduction in any medium, provided the original author and source are credited. 